\title{
Polymeric Helical Structures à la Carte by Rational Design of Monomers
}

Katherine Cobos, Rafael Rodríguez, Olaya Domarco, Berta Fernández, Emilio Quiñoá, Ricardo Riguera and Félix Freire

\section{Accepted Manuscript}

This document is the Accepted Manuscript version of a Published Work that appeared in final form in Macromolecules, copyright (c) 2020 American Chemical Society after peer review and technical editing by the publisher. To access the final edited and published work see: https://doi.org/10.1021/acs.macromol.0c00085

\section{Cite this:}

Macromolecules 2020, 53, 8, 3182-3193

\section{Copyright information:}

(C) 2020 American Chemical Society 


\title{
Polymeric Helical Structures à la carte by Rational
}

\section{Design of Monomers}

\author{
'Katherine Cobos, 'Rafael Rodríguez, tolaya Domarco, \#Berta \\ Fernández, tEmilio Quiñoá, tRicardo Riguera and tFélix Freire* \\ ${ }^{\dagger}$ Centro Singular de Investigación en Química Biolóxica e Materiais \\ Moleculares (CiQUS) and Departamento de Química Orgánica. \\ Universidade de Santiago de Compostela, 15782 Santiago de \\ Compostela (Spain) \\ \#Departamento de Química Física. Universidade de Santiago de \\ Compostela. 15782 Santiago de Compostela (Spain) \\ KEYWORDS: Helical Polymer, Poly(phenylacetylene), Circular \\ Dichroism, Dynamic behavior, Cis-cisoidal
}

\begin{abstract}
Preparation of helical structures à la carte by monomer design of dynamic helical polymers such as poly (phenylacetylene)s -PPAs - is a difficult task due to conformational freedom of the polyene backbone. Herein, we study the monomer/helical polymer scaffold relationship by preparation of two novel phenylacetylene monomer series substituted at the phenyl ring in ortho-, meta- or
\end{abstract}


para-positions with the two enantiomers of either $\alpha$-hydroxy- $\alpha-$ phenylacetic acid (1) and $\alpha$-chloro- $\alpha$-phenylacetic acid (S-2) linked through an anilide bond. These monomers were further polymerized, and their secondary structure and dynamic behavior analyzed. Compiling information from these studies, and the structural data for other PPAs found in literature, we can state that anilide linkages in p-substituted polymers tend to generate compressed cis-cisoidal polyene structures, which can be transformed into more elongated cis-transoidal ones by external stimuli, while benzamide linkages in p-substituted polymers form mainly cis-transoidal scaffolds. The macromolecular structure of PPAs is also largely affected by the aromatic substitution pattern, adopting more stretched scaffolds once the pendant group is placed in meta or ortho positions, due to the steric hindrance generated by placing this group closer to the backbone.

\section{INTRODUCTION}

Helices are structural motifs found in biomolecules such as DNA, peptides or polysaccharides, being closely related to their biological function. Therefore, during the last decades, the scientific community developed tools and protocols to synthetize and analyze the structure of these biomacromolecules. Because of this, nowadays it is possible to have a good control of their 
folding and to play with the properties and functions associated to the helical scaffolds.1-17

In parallel to these studies in biomolecules, novel materials that adopt helical structures, such as foldamers or helical polymers, were explored. These systems allow implementing the use of these new materials in fields such as sensing, ${ }^{18-27}$ chiral recognition, ${ }^{28-30}$ chiral stationary phases, ${ }^{31-32}$ asymmetric catalysts,33-39 chiral templates, 40-42 building blocks in supramolecular chemistry, ${ }^{43-47}$ optical switches ${ }^{48-49}$ and emitting devices among others. 50

In the special case of helical polymers, the preparation of helical structures by rational design of the parent monomers is a difficult task. The main reason is the lack of structural information related to these polymers. In literature, just a few research articles dealt with their secondary structure, most likely due to the problems that arise when one tries to extract structural information from materials made by monomer repeating units by using classical structural techniques. A great contribution to this field was done when Yashima's group developed a protocol to prepare 2D crystals from helical polymers. ${ }^{51-58}$ From these crystals it is possible to obtain high resolution AFM images and extract important helical parameters such as the helical pitch or the helical sense. However, the preparation of these self-assembled monolayers is not trivial, and therefore only a small number of helical polymers 
have been described using this approach. ${ }^{59-62}$ For this reason, most of the research articles found in literature that deal with helical polymers are focused only on their dynamic behavior but not on their secondary structure. The responsiveness ability of these compounds towards external stimuli such as chiral amplification, ${ }^{63-}$ 72 helix inversion, ${ }^{73-78}$ chiral communication, ${ }^{79}$ chiral conflict $80-81$ or helical sense enhancement ${ }^{82-83}$ can easily be studied by circular dichroism spectroscopy (CD). This technique has the advantages of requiring only a tiny amount of sample and of providing data very fast. Moreover, through CD it is also possible to study changes in the elongation of the polymer, which can also be studied by UVvis spectroscopy using the same sample.

In our group, we are interested not only in the dynamic response of these materials but also in their secondary structure. In helical polymers both parameters -dynamic behavior and structureare directly related, and therefore from a correct monomer design it should be possible to generate a material with an optimal structure for applications.

Herein, we want to demonstrate that it is possible to prepare a poly (phenylacetylene) where its stimuli-response behavior and elongation can be selected à la carte from a proper monomer design. To do that, it is necessary to play with the functional group used as linking agent between the polyene and the pendant group 


\begin{abstract}
(anilide/benzamide), but also with the aromatic substitution pattern of the PPA, the size and the conformation of the pendant group.

RESULTS AND DISCUSSION
\end{abstract}

Para-substituted PPAs. In a recent work we found that variations in the connection of an amide bond (benzamide or anilide) in parasubstituted phenylacetylene monomers can lead to the formation of either compressed or stretched helical structures. ${ }^{84}$ Thus, while p-PPAs bearing benzamides as pendant groups usually possess a cistransoidal skeleton (Scheme 1), with a dihedral angle between conjugated double bonds larger than $140^{\circ}$ (e.g., p-PPA bearing the benzamide of the phenylglycine methyl ester as pendant group -pPPA-PGME-; $\left.\omega_{1}=155^{\circ}\right), 74,75,84, p-P P A s$ bearing anilides as functional groups to link the pendants to the polyphenylacetylene main chain, produce a wide range of compressed (cis-cisoidal), 63-65,79,82-83 and stretched (cis-transoidal) ${ }^{84}$ helical structures. For instance, a p-PPA bearing the anilide of the $\alpha$-methoxyphenylacetic acid- $p-$ PPA-MPA; poly-3-adopts a cis-cisoidal polyene skeleton $\left(\omega_{1}=75^{\circ}\right), 65$ while a p-PPA bearing the anilide of the $\alpha$-methoxy- $\alpha$-phenyl- $\alpha-$ trifluoromethylacetic acid -p-PPA-MTPA- can adopt either a compressed cis-cisoidal helical structure in chloroform $\left(\omega_{1}=70^{\circ}\right)$ or a more stretched cis-transoidal helix when it is dissolved in 
$\operatorname{THF}\left(\omega_{1}=165^{\circ}\right) .{ }^{85-86} \mathrm{All}$ these polymers are dynamic, and their dynamic behavior is related to the conformational equilibrium of the pendant groups, which can be altered by the action of external stimuli. $65,79,84$

Thus, in order to increase the number of cis-cisoidal scaffolds and demonstrate that the anilide linkage promotes its formation, two new monomers were designed taking into account their two possible absolute configurations at the chiral centre: the 4ethynylanilide of $(S)$ - and $(R)$ - $\alpha$-hydroxy- $\alpha$-phenylacetic acid $[p-$ $m-(S)-1$ and $p-m-(R)-1]$ (Eigure 1a), and the 4-ethynylanilide of $(S)$ - and $(R)-\alpha$-chloro- $\alpha$-phenylacetic acid $[p-m-(S)-\mathbf{2}$ and $p-m-(R)-$ 2] (Figure 1b). These monomers were constructed taking into account the previously reported $p-p o l y-(S)-3$ and $p-p o l y-(R)-3$ that bears the anilide of the $(S)$ - and $(R)$ - $\alpha$-methoxy- $\alpha$-phenylacetic acid $[\mathrm{p}-$ m-(S)-3] (Figure 1c, f). Two replacements of the oMe group were done in $p-m-3$ to design the new $p-m-1$ and $p-m-2$ monomers: i) by a hydroxy group, which increases the polarity of the pendant and can be involved in the formation of hydrogen bond interactions [p-m1]; and ii) by a chlorine, which is a large electronegative atom [p-m-2]. During this monomer design we avoided bulky groups in order to minimize the induction of cis-transoidal structures in the corresponding PPAs. With the presence of large substituents the steric hindrance introduced into the cis-cisoidal helix would 
be released through elongation of the polyene backbone, generating, therefore, a more stretched scaffold.

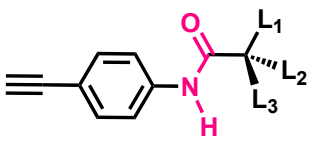

p-PA-anilide

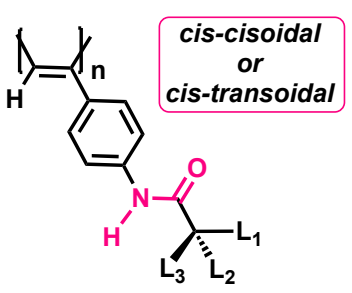

p-PPA-anilide

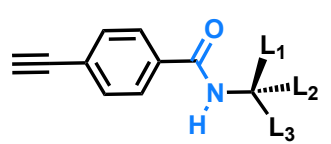

p-PA-benzamide

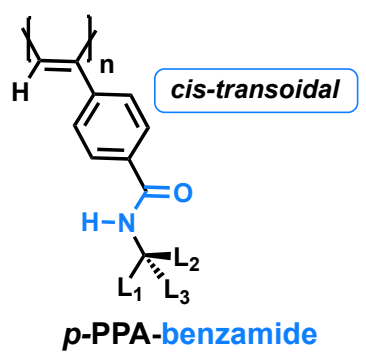

Scheme 1. PPAs with anilide and benzamide connectors.

Most of the p-PPAs studied in the literature resort to benzamide connectors -generating cis-transoidal polyene skeletons-. ${ }^{73,75,84,87-}$ 90 However, PPAs bearing linking moieties such as anilide ${ }^{91}$ or ester 92-103 groups -connectors that can generate cis-cisoidal configurations- have not been deeply investigated from the structural point of view.

Thus, monomers $p-m-(S)-\mathbf{1}, p-m-(R)-\mathbf{1}, p-m-(S)-\mathbf{2}$ and $p-m-(S)-\mathbf{1}$ were prepared and submitted to polymerization with $\left[\{\mathrm{Rh}(\mathrm{nbd}) \mathrm{Cl}\}_{2}\right]$ (nbd= 2,5-norbornadiene) as catalyst ${ }^{104-110}$ affording poly (phenylacetylene)s p-poly-(S)-1, p-poly-(R)-1, p-poly-(S)-2, and p-poly-(R)-2 (Figure 1d, e). The synthetized polymers showed ${ }^{1} \mathrm{H}-\mathrm{NMR}$ (5.6-5.8 ppm) and Raman signals indicative of a cis-polyene backbone (see SI: S21). CD studies were carried out for p-poly- 
(S) -1 and p-poly-(S)-2 to determine their dynamic behavior. CD spectra of p-poly-(R)-1 and p-poly-(R)-2 in different solvents show identical CD traces to their corresponding counterparts ppoly-(S)-1 and p-poly-(S)-2 but with opposite sign due to their enantiomeric relationship (See SI) .

a)<smiles>C#Cc1ccc(NC(=O)C(O)(O)C(C)=CCC)cc1</smiles>
H-Bond Interactions p-m-(S)-1

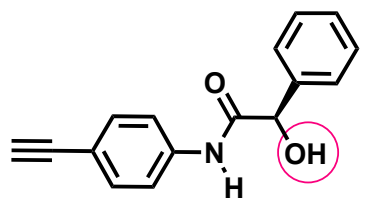

p-m-(R)-1

d)

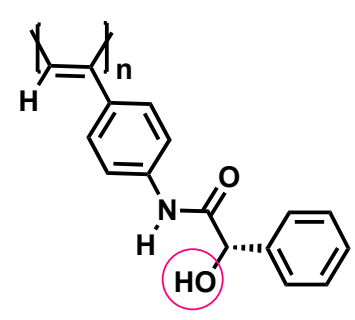

p-poly-(S)-1

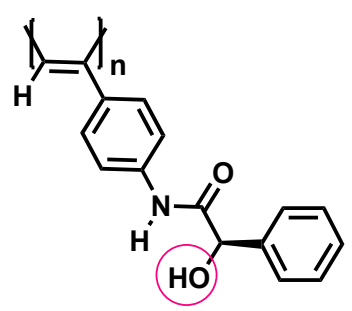

p-poly- $(R)-1$ b)

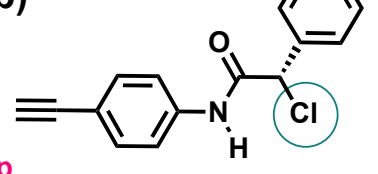

Electrowithdrawing

p-m-(S)-2

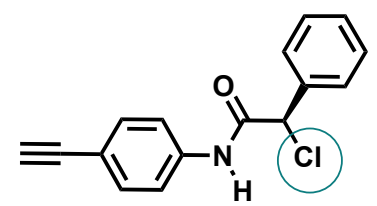

$p-\mathrm{m}-(R)-2$

e)

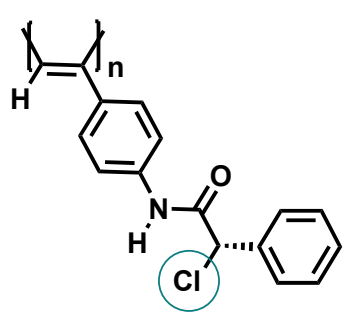

p-poly-(S)-2

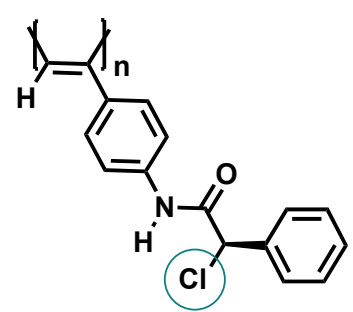

p-poly- $(R)-2$ c)<smiles>C#Cc1ccc(NC(=O)[C@H](OC)c2ccccc2)cc1</smiles>

p-m-(S)-3

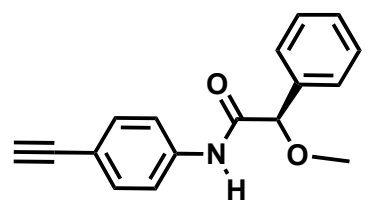

p-m-(R)-3

f)

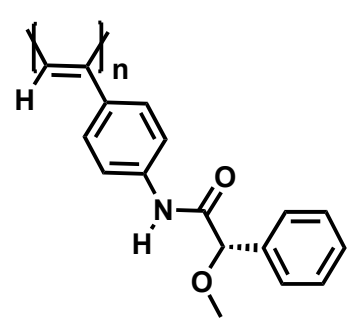

p-poly-(S)-3

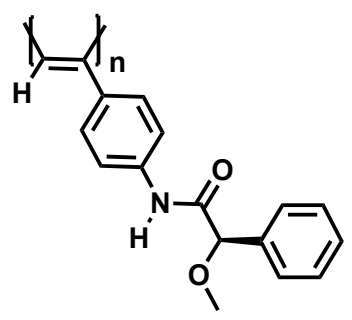

p-poly- $(R)-3$

Figure 1. Structures of (a) $p-m-(S)-\mathbf{1}$ and $p-m-(R)-\mathbf{1}$, (b) $p-m-(S)-\mathbf{2}$ and $p-m-(R)-2$ and (c) $p-m-(S)-3$ and $p-m-(R)-3$ and their corresponding polymers (d) $p-p o l y-(S)-1$ and $p-p o l y-(R)-1$, (e) p- 
poly-(S)-2 and p-poly-(R)-2, and (f) p-poly-(S)-3 and p-poly-(R)3.

Interestingly, comparison of the CD spectra obtained from p-poly$(S)$-1, p-poly-(S)-2 and p-poly-(S)-3, showed a different dynamic behavior due to the different conformational configurations at the pendant groups (Figure 2). For instance, while p-poly-(S)-3 is highly dynamic in low-polar and non-donor solvents such as chloroform -showing an equilibrium between two almost equally populated pendant conformations-, $p$-poly-(S)-1 and p-poly-(S)-2 adopt an excess of a single-handed helix -the conformational equilibrium of the pendant group is shifted towards the most stable pendant one- (Figure 2a) .

Thus, while p-poly-(S)-1 is sensitive to polar changes $-\mathrm{CD}(+)$ at $380 \mathrm{~nm}$ in low polar solvents such as $\mathrm{CHCl}_{3}$ or $\mathrm{THF}$ and (-) in polar solvents such as DMF- (Figure 2c), p-poly-(S)-2 is sensitive to the donor character of the solvent. p-poly-(S)-2 shows CD (+) at $340 \mathrm{~nm}$ in non-donor solvents (e. g., $\mathrm{CHCl}_{3}$ ), while a CD (-) accompanied with a red shift absorption of the polyene region (390 nm) is observed in donor solvents also with independence of their polar character, e. g., THF (low polar), DMF (polar)-(Figure 2d). These different responses to stimuli observed in $p$-poly- $(S)-\mathbf{1}, p-$ poly-(S)-2 and p-poly-(S)-3 are directly related to the different conformational compositions at the pendant groups, where different 
bonds are involved. Therefore, we analyzed the conformational structure at the pendants in p-poly-(S)-1 and p-poly-(S)-2.
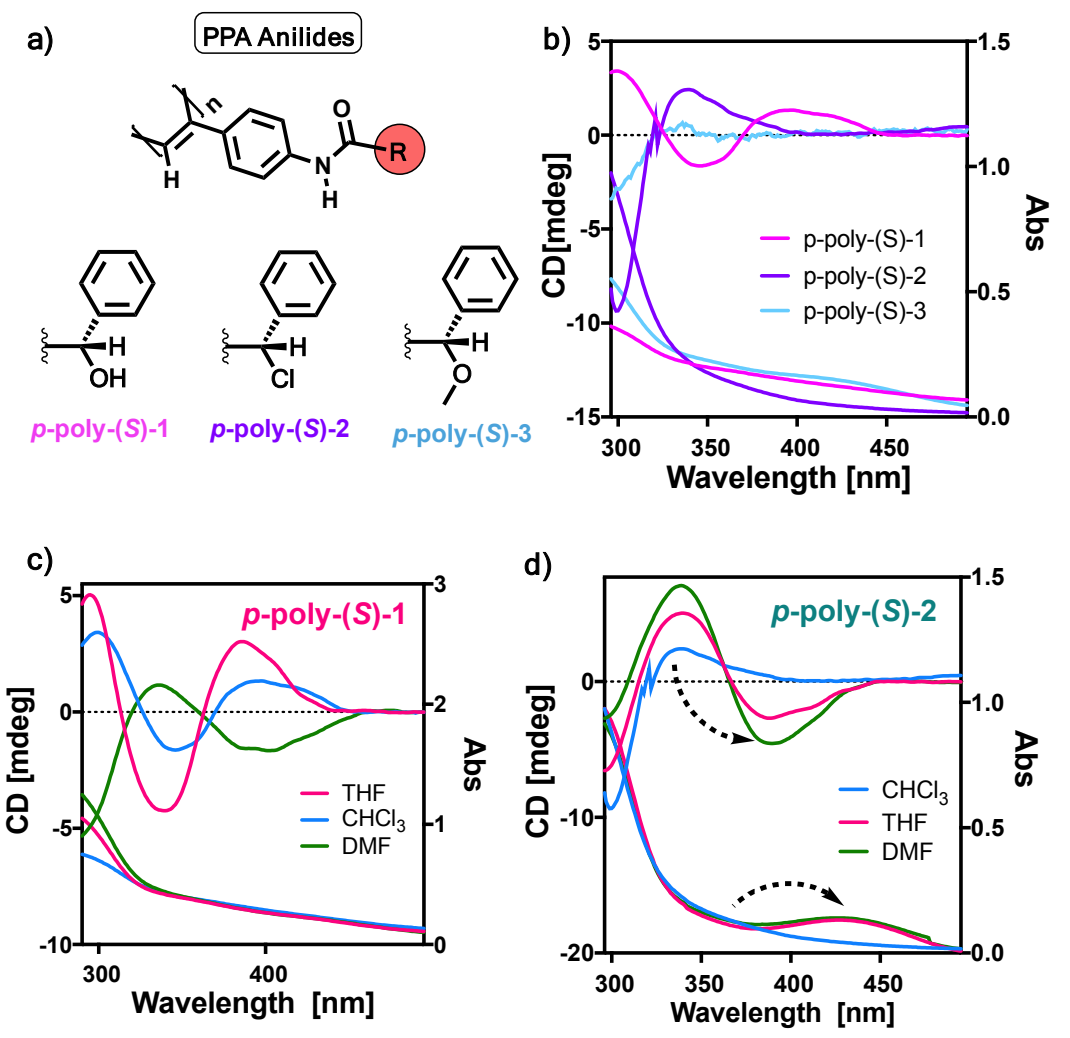

Figure 2. (a) Structures of $p-p o l y-(S)-1, p-p o l y-(S)-2$ and $p-p o l y-$ (S)-3. (b) Comparison of the CD/UV-vis spectra p-poly-(S)-1, ppoly-(S)-2 and p-poly-(S)-3 in $\mathrm{CHCl}_{3}$. (c) CD/UV-vis spectra of $p^{-}$ poly-(S)-1 in different solvents showing helical sense modulation by polar effects (d) CD/UV-vis spectra of p-poly-(S)-2 in different solvents showing helical sense modulation and stretching by donor/acceptor effects.

From previous studies we know that in the case of p-poly-(S)-3 dissolved in $\mathrm{CHCl}_{3}$, the pendant group exists as a 1:1 equilibrium between two conformers (sp, synperiplanar oriented carbonyl and 
methoxy groups; and ap, antiperiplanar oriented carbonyl and methoxy groups) that places the bulkiest group in orientations that favor a specific helical sense for each conformer. ${ }^{46,66}$

X-ray studies of monomers $p-m-(R)-\mathbf{1}$ and $p-m-(R)-\mathbf{2}$ show an antiperiplanar orientation of the carbonyl and hydroxy group in the case of $p-m-(R)-1$, and of the carbonyl group and the chlorine atom in $p-m-(R)-2$ (Figure $3 a, b)$.

CD studies of $p-m-(S)-1$ in different solvents show a (-) CD Cotton effect at $270 \mathrm{~nm}$, which is in agreement with an ap conformation between the carbonyl and the hydroxyl group (Figure 3c). The addition of different metal perchlorates such as $\mathrm{Ba}\left(\mathrm{ClO}_{4}\right)_{2}$ induces a conformational change forcing the orientation between the carbonyl and hydroxy group from an ap conformation towards a sp one (Figure 3c). ${ }^{46}$

Similar studies were carried out for $p-m-(S)-\mathbf{2}$. In this case, the monomer responds only to the donor character of the solvent and not to its polarity. CD spectra of $p-m-(S)-\mathbf{2}$ show a negative CD Cotton effect at $275 \mathrm{~nm}$ in non-donor solvents, independently of its polar character (Figure 3d). Moreover, this CD can be inverted and red-shifted to $290 \mathrm{~nm}$ in donor solvents, due to the interaction of the amide group with that kind of solvents (Figure 3d, S8). This supramolecular interaction favors a conformational change of the amide group from trans (non-donor) to cis (donor), while the orientation between the carbonyl group and the chlorine atom 
remains unaltered in an ap conformation (Figure 3d, S8). A similar situation was previously observed by our group in a polymer that bears the anilide of $\alpha$-methoxy- $\alpha$-phenyl- $\alpha$-trifluoromethylacetic acid (MTPA) as pendant but in such case, the polymer responds not only to the donor character of the solvent but also to its polarity.85-86 Therefore, by comparison of both PPAs, we can anticipate that the presence of an electron withdrawing group such as a chlorine atom or a $\mathrm{CF}_{3}$ group in the pendant makes the anilide group very acidic. Now, the pendant can strongly interact with donor solvents affecting the cis/trans conformational composition of the amide group. ${ }^{18}$ 
a)

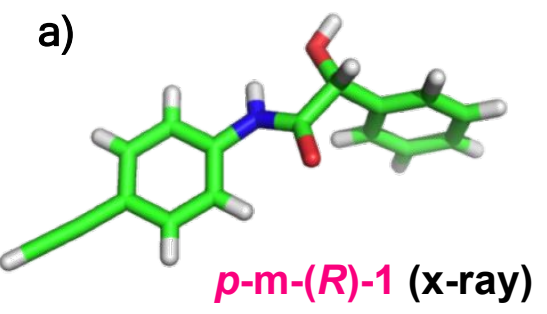

c) p-m-(S)-1<smiles>C#Cc1ccc(NC(=O)[C@H](O)c2ccccc2)cc1</smiles>

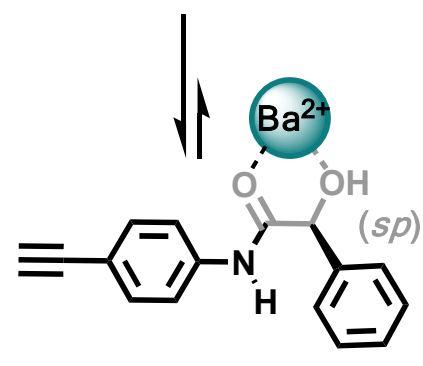

d)

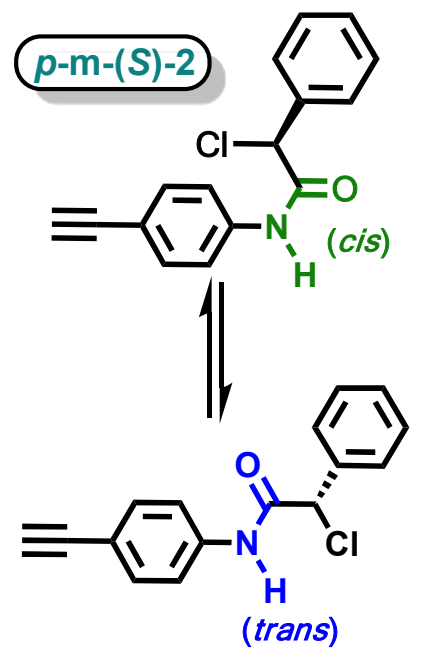

b)
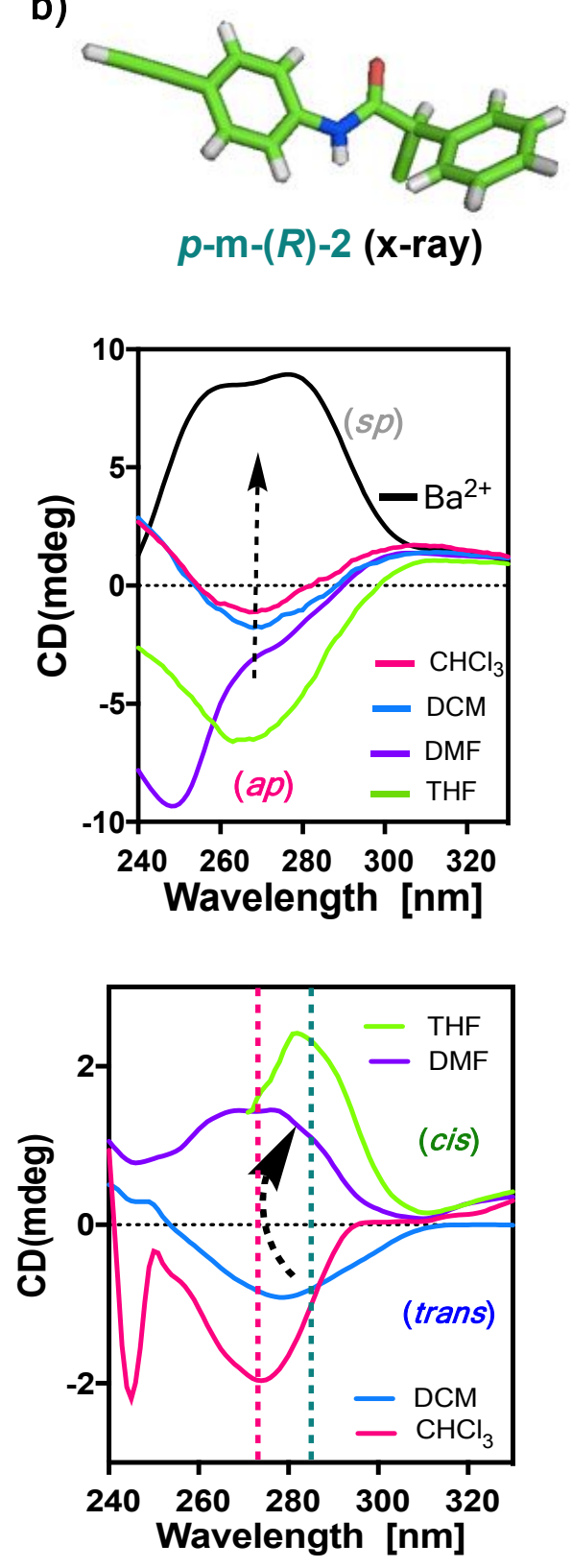

Figure 3. X-Ray structures of (a) $p-m-(R)-1$ and (b) $p-m-(R)-2$. (c) Schematic illustration of the conformational switch of $p-m-(S)-1$ between ap and sp conformers triggered by metal coordination and ECD spectra supporting this conformational switch. (d) Schematic illustration of the conformational switch of $p-m-(S)-\mathbf{2}$ between the 
cis- and trans- amide triggered by solvent donor effects and CD studies showing this conformational switch.

Conformational studies in the corresponding polymer p-poly-(S)1 show a similar behavior, i.e., a conformational switch between the ap and the sp conformers at the pendant group induced by solvent polarity changes or by the addition of metal ions (Figure 4). Thus, on the one hand, p-poly-(S)-1 adopts a major antiperiplanar conformation for the carbonyl and hydroxy groups in low-polar solvents, which commands a $\mathrm{CD}(+)$ at the vinylic region (390 nm) (Figures 4a,d). On the other hand, a synperiplanar orientation of these groups can be induced by increasing the polarity of the solvent or by the addition of $\mathrm{Ba}\left(\mathrm{ClO}_{4}\right)_{2}$ (Figure $4 \mathrm{a}-$ b, d). This conformational change is accompanied by an inversion of the helical sense CD (-) at $390 \mathrm{~nm}$ (Figure 4a,b). 

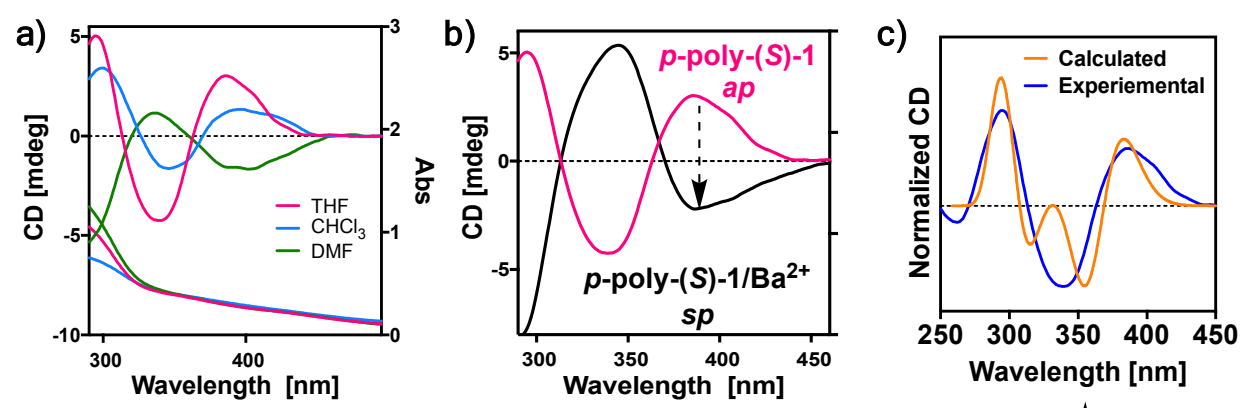

d)
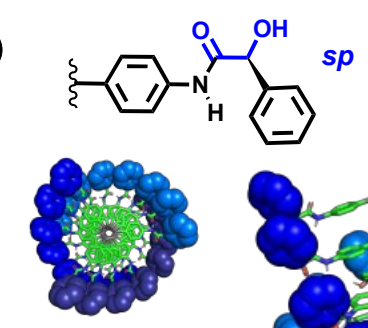

Pendants $M(\mathrm{e})$
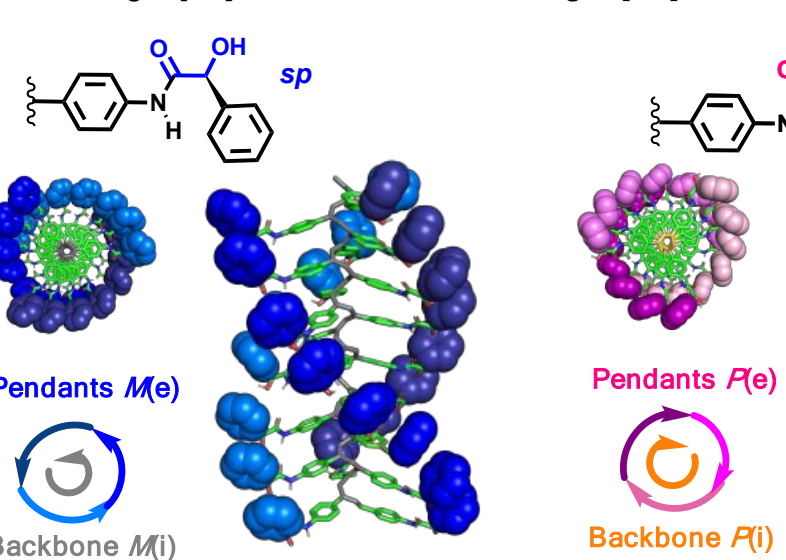

Backbone $M(\mathrm{i})$

Helix

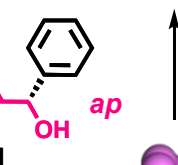

(Polar Solvents $\left./ \mathrm{Ba}^{2+}\right) \longrightarrow$ cis-cisoidal PPA $\longrightarrow$ (Low Polar Solvents)

Figure 4. (a) CD/UV-Vis spectra of $p-p o l y-(S)-1$ in solvents of different polarity displaying helix inversion by polar effects. (b) CD spectra of the helix inversion of p-poly-(S)-1 triggered in $\mathrm{CHCl}_{3}$ by the addition of $\mathrm{Ba}^{2+}$. (c) Comparison of the calculated vs experimental ECD spectra of a cis-cisoidal structure for p-poly(S) -1 describing a $P$ helix. (d) Schematic illustration of the helix inversion process of $p-p o l y-(S)-1$.

In the case of p-poly-(S)-2, a helix inversion is produced by changes in the donor character of the solvent, while no structural effects are observed by changes in solvent polarity (Figure 5b). This response to the donor character is due to the selective 
manipulation of the cis/trans conformational composition of the amide group (confirmed by IR and STD experiments, Figure S21). Thus, while in non-donor solvents $\left(\mathrm{CHCl}_{3}\right)$ the amide adopts a preferred trans conformation, in donor solvents (THF or DMF), the amide adopts a major cis conformation which is accompanied with a helix inversion (CD (+), $\lambda=337 \mathrm{~nm}$ and $\mathrm{CD}(-), \lambda=393 \mathrm{~nm}$ ) and stretching of the polyene backbone (bathochromic shift of polyene band from $\lambda=337$ to $\lambda=393 \mathrm{~nm}$ ) (Figures $5 \mathrm{~b}$ and $\mathrm{S} 15) .{ }^{18}$

Next, structural studies were carried out to determine the secondary structure of $p-p o l y-(S)-\mathbf{1}$ and $p-p o l y-(S)-\mathbf{2}$.

DSC studies on p-poly-(S)-1 reveal the presence of a cis-cisoidal polyene skeleton, 84,111 with an exothermic peak at $243.0{ }^{\circ} \mathrm{C}$ corresponding to the thermal transition from cis-cisoidal to trans-transoidal arrangements (See Figure s22).

This structure is in agreement with the structure previously obtained for p-poly-(S)-3.65 A computational study [DFT(rCAMB3LYP)/3-21G $]^{112-113}$ on a $P$ helix of an $n=12$ oligomer of $p-p o l y-$ (S) $\mathbf{- 1}$ possessing a cis-cisoidal polyene skeleton and an antiperiplanar orientation of the carbonyl and hydroxy groups at the pendants shows a CD trace in agreement with the experimental one (Figure 4c), corroborating the formation of a cis-cisoidal structure, where the internal and the external helices rotate in the same direction (figure 4d). The dihedral angles used as input 
to build an approximate structure for p-poly-(S)-1 were extracted from different structural techniques (see SI).

DSC studies for p-poly-(S) -2 show different thermograms depending on the degree of the donor solvent character. A typical ciscisoidal thermogram was obtained for p-poly-(S)-2 in non-donor solvents, while a cis-transoidal one was obtained in donor solvents (Figure $5 \mathrm{~d}, \mathrm{e}) \cdot{ }^{111}$

The presence of a cis-cisoidal polyene skeleton for p-poly-(S)2 in non-donor solvents was further confirmed by AFM studies (Figure 5a). In such a case, it was possible to generate a 2D crystal which allowed us to obtain high-resolution AFM images and therefore, extract important helical parameters such as the helical pitch $(3.1 \mathrm{~nm})$ and the orientation of the external part of the helix, in this case a $P$ helix. These helical parameters correspond to a cis-cisoidal backbone $\left(\omega_{1}=65^{\circ}\right)$, with three residues per turn, and where the internal helix described by the polyene main chain, and the external helix described by the pendant group, rotate in the same direction (i.e., $P$ sense, Figure 5a). 

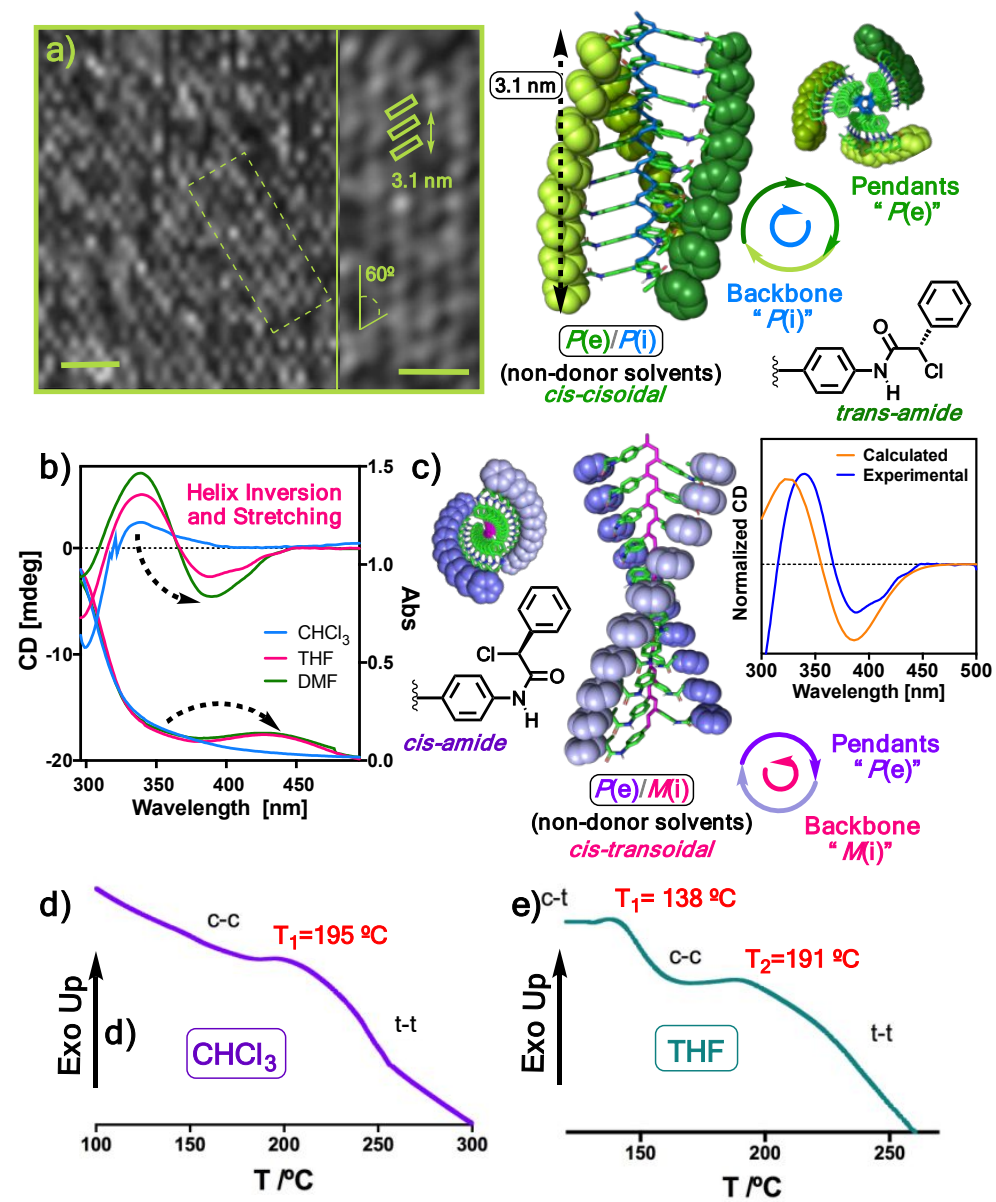

Figure 5. (a) AFM image and cis-cisoidal structure of p-poly-(S)-2 in non-donor solvents (i.e., $\left.\mathrm{CHCl}_{3}\right) \quad($ scale bar $=10 \mathrm{~nm}) .(\mathrm{b}) \mathrm{CD} / \mathrm{UV}-$ Vis spectra of p-poly-(S)-2 in solvents with different donor properties displaying helix inversion and stretching due to ciscisoidal to cistransoidal isomerization process mediated by modulation of cis-/trans- amide conformation. (c) Cis-transoidal structure of p-poly-(S)-2 in donor solvents (e.g., THF or DMF) and comparison of the calculated vs experimental ECD spectra. (d) DSC thermogram indicating the cis-cisoidal structure of p-poly-(S)-2 in non-donor solvents (i.e., $\mathrm{CHCl}_{3}$ ). (e) DSC thermogram indicating 
the cis-transoidal structure of $p$-poly-(S)-2 in donor solvents (i.e., THF) .

When talking about the architecture of these polymers, it is necessary to point out that, in every poly (phenylacetylene), two "coaxial helices" are present: external (defined by the pendants, detected by AFM) and internal (defined by the polyene backbone, detected by $C D$, and their respective helical senses can be coincident or not. 51,56

In donor solvents, a more stretched helix is generated accompanied by a bathocromic effect in the CD and UV spectra (Figure 5b). DSC studies show the presence of a cis-transoidal skeleton in donor solvents (Figure 5e).

A computational [DFT(rCAM-B3LYP)/3-21G ]112-113 study on a $M$ helix of an $\mathrm{n}=12$ oligomer of $p$-poly-(S)-2 possessing a cis-transoidal polyene skeleton with an antiperiplanar orientation of the carbonyl group and the chlorine atom and an amide group in cis- at the pendant, shows a CD trace in agreement with the experimental one (Figure 5c). The dihedral angles used as input to build an approximate structure for p-poly-(S)-2 were extracted from different structural techniques (see SI).

Theoretical CD studies corroborate therefore, the formation of a cis-transoidal structure, where the internal and the external helices rotate in opposite directions. 
From these studies we can conclude that in p-PPAs bearing anilide groups to connect the backbone and the pendants, the polyene chain can adopt a cis-cisoidal scaffold, which can be shifted towards a cis-transoidal one by introducing a large steric hindrance as consequence, for instance, of a trans/cis amide conformational equilibrium, or the presence of bulky substituents at the pendant. To sum up, the dynamic behavior of these p-PPAs is directly related to the conformational flexibility of the pendant groups, where selective manipulation of the conformational equilibria can lead to a selective helical sense of the PPAs.

Meta-substituted PPAs. Next, we studied the structure and dynamic behavior of m-poly-(S)-1 and m-poly-(S)-2, substituted in meta position.

X-ray structures of monomers $m-m-(S)-1$ and $m-m-(S)-2$ show the presence of an antiperiplanar orientation of the carbonyl and hydroxy group in $m-m-(S)-\mathbf{1}$, and between the carbonyl and the chlorine atom in the case of $m-m-(S)-\mathbf{2}$ (Figure 6a). Moreover, from CD studies it was found that the same conformation was kept for both monomers in different solvents independently of their donor and polar character (See Figure S7). CD studies of the corresponding polymers, $m$-poly- $(S)-\mathbf{1}$ and $m-p o l y-(S)-\mathbf{2}$ indicate, as expected, the presence of an excess of a single-handed helix, where its helical sense is not affected by the donor or polar character of the solvent (Figures 6b, d). These results are in agreement 
with those obtained for $m$-poly-(S)-3,114 corroborating therefore that meta-substituted polymers show a less dynamic behavior than the para-substituted ones. Furthermore, the CD traces obtained for m-poly-(S)-1 and $m$-poly-(S)-2 are very similar to that obtained from m-poly-(S)-3, with a very strong positive band close to 240 $\mathrm{nm}$ (band in part associated to the conformation of the pendant, $3^{\text {th }}$ Cotton effect) and two smaller bands centered at around $320 \mathrm{~nm}$ (negative) and $380 \mathrm{~nm}$ (positive) in the polyene region (Figures $6 \mathrm{~b}, \mathrm{~d})$

VT-CD studies show that the intensities of the two polyene bands evolve as expected for an equilibrium mixture between a more stable compressed helix (i.e., cis-cisoid, 3/1), which increases both its population and band intensities ( $1^{\text {st }}$ and $2^{\text {nd }}$ Cotton effects) at lower temperatures; and a less stable stretched helix (i.e., cistransoid, 2/1), that increases its population at higher temperatures accompanied by a decrease in the band intensities. In accordance with this, the UV band of $m$-poly- $(S)-\mathbf{1}$ and $m$-poly-(S)-2 at $400 \mathrm{~nm}$ suffers a hypsochromic shift when the temperature decreases (smaller polyene conjugation, cis-cisoid) and a bathochromic shift at higher temperatures (larger polyene conjugation, cis-transoid, Figures 6c, e-f). ${ }^{82-84}$

ACS Paragon Plus Environment 
a)
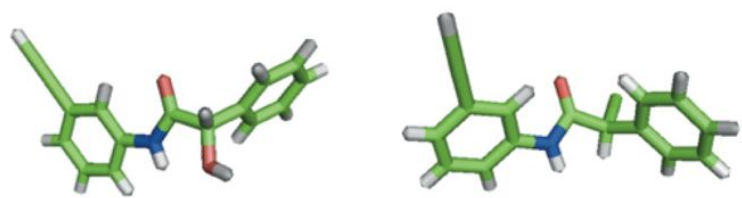

$m-\mathrm{M}-(S)-1$

$m-\mathrm{M}-(S)-2$

b)
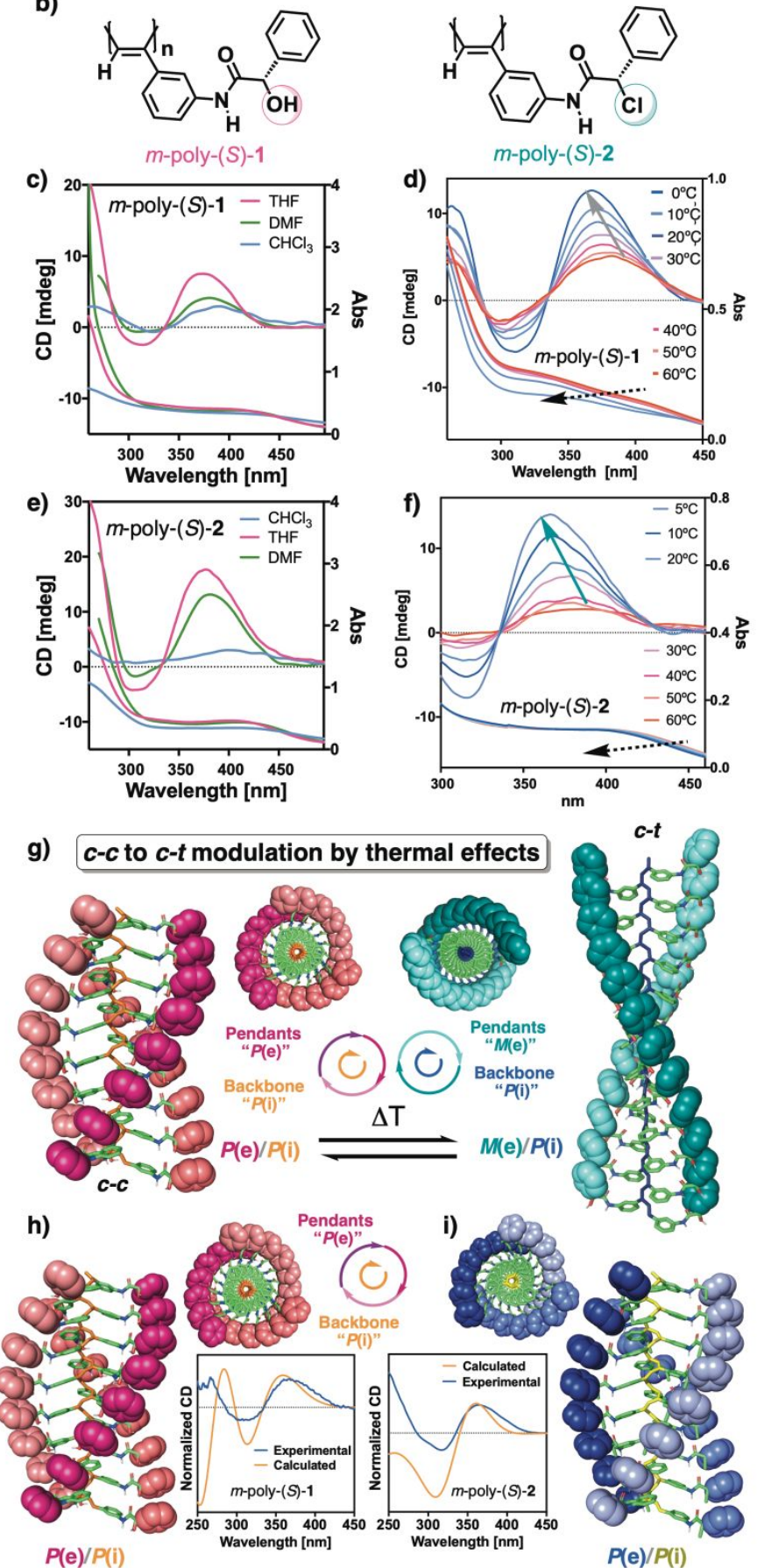

Figure 6. (a) X-Ray structure of $m-m-(S)-1$ and $m-m-(S)-\mathbf{2}$.

Chemical structure of m-poly-(S)-1 and m-poly-(S)-2. (c) CD/UV- 
Vis spectra of m-poly-(S)-1 in different solvents. (d) VT-CD/VTUV-Vis spectra of m-poly-(S)-1. (e) CD/UV-Vis spectra of m-poly(S)-2. (f) VT-CD/VT-UV-Vis spectra of m-poly-(S)-2. (g) Schematic illustration of the $c-t$ to $c^{-c}$ contraction modulation by thermal effects. (h) Structure and calculated vs experimental ECD spectra of $m$-poly-(S)-1. (i) Structure and comparison of the calculated vs experimental ECD spectra of $m-p o l y-(S)-\mathbf{2}$.

Computational studies [DFT(rCAM-B3LYP)/3-21G ]112-113 on $P$ helices of $\mathrm{n}=12$ oligomers, with cis-cisoidal polyene skeletons and an antiperiplanar orientation of the carbonyl and the hydroxy group for m-poly-(S)-1 and an antiperiplanar orientation of the carbonyl group and the chlorine atom for m-poly-(S)-2, show in both cases CD traces in agreement with the experimental ones, corroborating therefore the formation of a predominant cis-cisoidal structure, where the internal and the external helices rotate in the same direction (Figure 6g-h).51,56 The dihedral angles used as input to build an approximate structure for $m$-poly-(S)-1 and $m$-poly-(S)-2 were extracted from different structural techniques (see SI).

CD spectra of the enantiomeric counterparts $m$-poly-(R)-1 and $m^{-}$ poly-(R)-2 in different solvents are opposite to p-poly-(S)-1 and p-poly-(S)-2 due to their mirror image relationship (See SI).

Ortho-substituted PPAs. Finally, structural and dynamic studies in ortho-substituted PPAs were carried out. In the literature there 
are just a few examples of o-PPAs due to the difficulty to obtain them by using the standard protocol [i.e., with Rh(I) catalyst]. This synthetic problem is generated by the large steric hindrance found in these materials, due to the pendant group being close to the polyene main chain. In a previous work, ${ }^{84}$ we found that only a monomer which affords a cis-cisoidal PPA scaffold in the parasubstituted series can succeed in the preparation of the orthosubstituted one, while those that generate a cis-transoidal scaffold in the para-substituted series have no chance to polymerize when they are ortho substituted. We can explain this assumption based on the larger rotational freedom of a cis-cisoidal skeleton $\left(\omega_{1}<90^{\circ}\right)$ until reaching a planar structure $\left(\omega_{1}=180^{\circ}\right) .{ }^{40-}$ 42,84 On the contrary a cis-transoidal polymer $\left(\omega_{1}>90^{\circ}\right)$, presents a turning range until reaching a planar structure with $\omega_{1}$ lower than $90^{\circ}$. This rotational freedom is the one used by the polyene backbone to accommodate the pendant in the ortho- position, presenting therefore more capacity for this a cis-cisoidal polymer than a cis-transoidal one.

Herein we have prepared four para-substituted polymers, p-poly(S) -1, p-poly-(R)-1, p-poly-(S)-2 and p-poly-(R)-2, that adopt a cis-cisoidal polyene skeleton (see above). Hence, these polymers are great candidates to obtain the corresponding o-poly-(S)-1, opoly- $(R)-1, \quad o-p o l y-(S)-2$ and o-poly-(R)-2. 
Ortho substituted monomers $o-m-(S)-\mathbf{1}, \quad o-m-(R)-\mathbf{1}, \quad o-m-(S)-\mathbf{2}$ and o-m-(R)-2 were synthetized and submitted to polymerization using the standard conditions with a Rh(I) catalyst (See Table S1). Interestingly in both cases the ortho-substituted PPAs were obtained in good yields.

X-ray structures of monomers o-m-(S)-1 and o-m-(R)-2 indicate the presence of an antiperiplanar orientation of the carbonyl and hydroxy group in $0^{-m-(S)-1}$, and the carbonyl and the chlorine atom in the case of o-m-(R)-2. Moreover, from CD studies it was found that the same conformation was kept for both monomers in different solvents independently of their donor and polar character (See Figures $\mathrm{S} 7 \mathrm{e}-\mathrm{f})$.

UV studies of the corresponding polymers -o-poly-(S)-1 and opoly-(S)-2- in different solvents showed, as expected, the polyene band close to $500 \mathrm{~nm}$. Additionally, a bathochromic shift is observed when the UV trace for the ortho-substituted PPAs are compared to the para- and meta-substituted ones. This red shift is accompanied with a color change, from yellow to red that indicates a large stretching of the helical scaffold (Figures 7c and 7f). 
a)
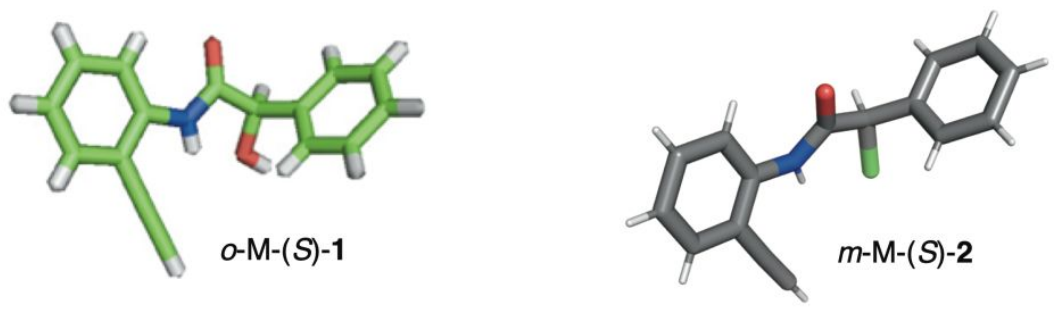

b)<smiles>CC=Cc1ccccc1NC(=O)C(C)(O)c1ccccc1</smiles>

o-poly-(S)-1<smiles>C/C=C/c1ccccc1NC(=O)C(Cl)(c1ccccc1)c1ccccc1</smiles>

c)

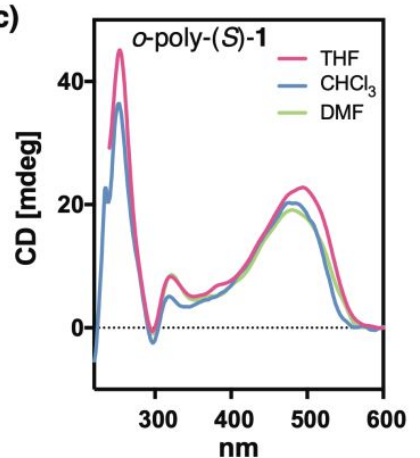

f)

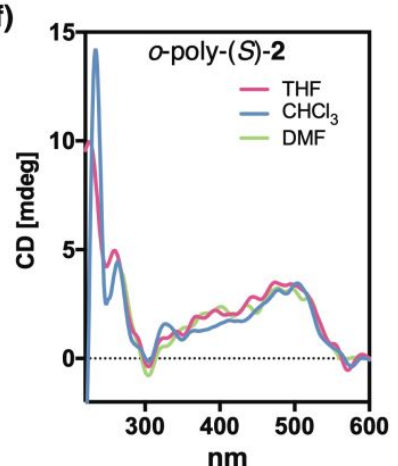

i)

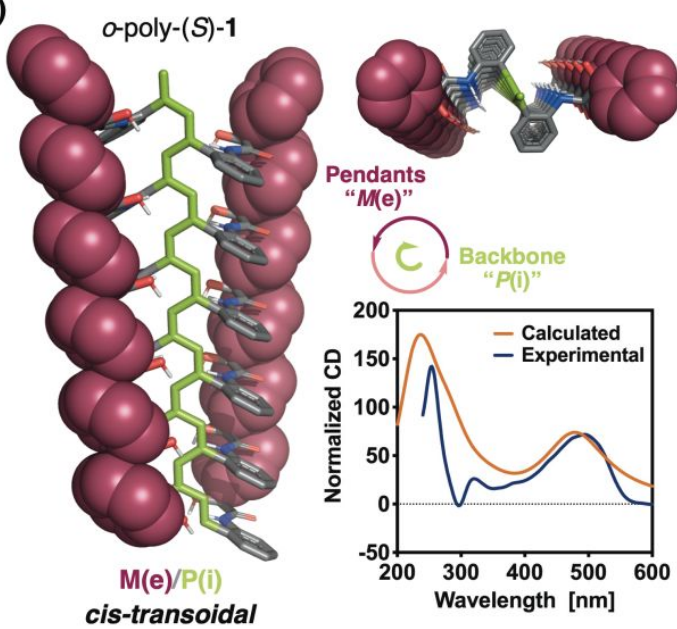

d)

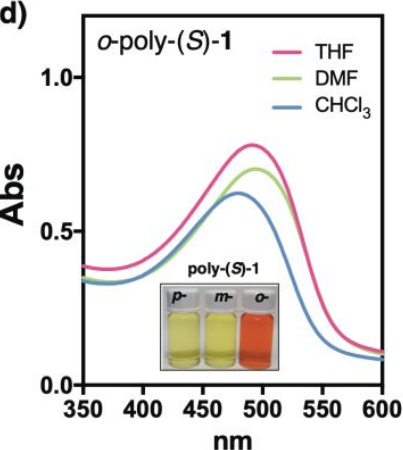

g)

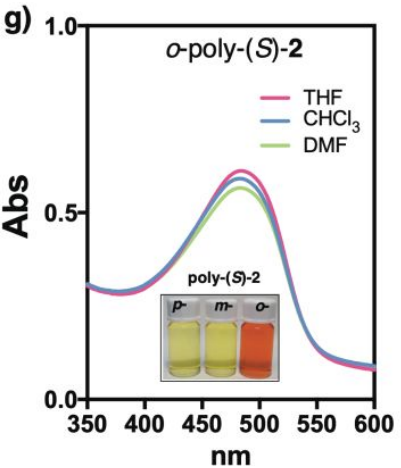

j) e)

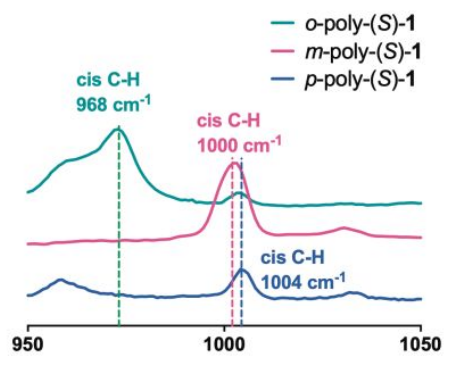

h)

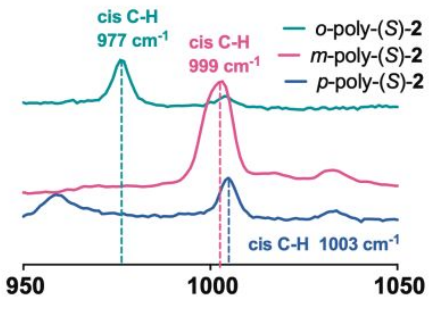

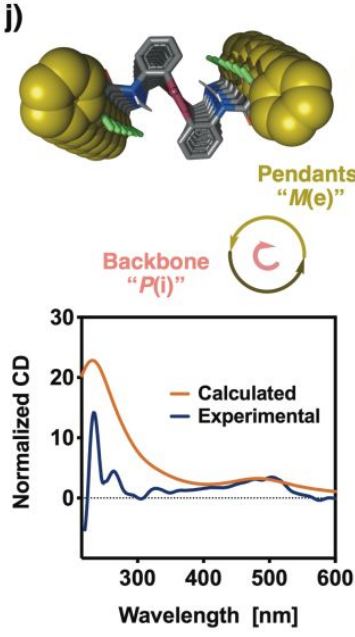

o-poly-(S)-2

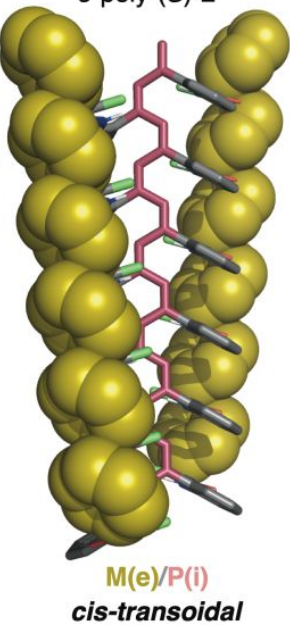


Figure 7. (a) X-Ray structure of $o-m-(R)-\mathbf{1}$ and $o-m-(R)-2$. (b) Chemical structure of o-poly-(S)-1 and o-poly-(S)-2. (C) ECD spectra of o-poly-(S)-1 in different solvents. (d) UV-vis of opoly-(S)-1 in different solvents. (e) Raman spectra of the poly-1 family showing blue shift in the cis-C-H band as the PPA backbone stretches. (f) ECD spectra of o-poly-(S)-2 in different solvents. (g) UV-vis of o-poly-(S)-2 in different solvents. (h) Raman spectra of the poly-2 family showing blue shift in the cis-C-H band as the PPA backbone stretches. (i) Structure and comparison of the calculated vs experimental ECD spectra of o-poly-(S)-1. (j) Structure and comparison of the calculated vs experimental ECD spectra of o-poly-(S)-2.

The results obtained for o-poly-(S)-1 and o-poly-(S)-2 are coincident with the ones obtained previously for o-poly-(S)-3, indicating the presence of a cis-transoidal polyene skeleton with $\omega_{1}>170^{\circ}$. CD studies on o-poly-(S)-1 and o-poly-(S)-2 indicate, as expected, the presence of an excess of a single-handed helix, where its helical sense it is not affected by the solvent (Figure 7b,e). Interestingly, we found that o-poly-(S)-1 is sensitive to the donor character of the solvent presenting a red shift when is dissolved in THF or DMF compared to the CD/UV trace obtained in $\mathrm{CHCl}_{3}$ (Figure 7b, c). In the case of o-poly-(S)-2, the CD and UV traces are almost identical in these solvents (Figure 7e, f). Raman 
spectra corroborated the presence of a very stretched cis polyene skeleton with a $\mathrm{C}-\mathrm{H}$ band at $968 \mathrm{~cm}^{-1}$ for o-poly-(S)-1 and $977 \mathrm{~cm}^{-1}$ for o-poly-(S)-2. In fact, this frequency is much lower than in the meta and para counterparts $\left[1000\right.$ and $1004 \mathrm{~cm}^{-1}$ for $m-$ and $p-$ poly-(S)-1 and 999 and $1003 \mathrm{~cm}^{-1}$ for $m$ - and p-poly-(S)-2], clearly indicating that the helical backbones of o-poly-(S)-1 and o-poly(S) -2 are much more stretched (Figures $7 \mathrm{~d}$ and $7 \mathrm{~g}$ ). ${ }^{82-83}$

Computational studies [DFT(rCAM-B3LYP)/3-21G ] $112-113$ on a $P$ helix of a $\mathrm{n}=12$ oligomer, possesing a cistransoidal polyene skeleton $\left(\omega_{1}=175^{\circ}\right)$ with an antiperiplanar orientation of the carbonyl and hydroxy group for o-poly-(S)-1, and an antiperiplanar orientation of the carbonyl group and the chlorine atom for o-poly-(S)-2 show, in both cases, CD traces coincident with the experimental ones, corroborating therefore the formation of highly stretched cistransoidal structures, where the internal and the external helices rotate in opposite directions (Figures 7h-i).

So, we can state that it is possible to obtain an orthosubstituted polymer from a monomer which affords a cis-cisoidal PPA scaffold in the para-substituted series. Moreover, the location of the pendant group very close to the polyene main chain results in the adoption of a highly stretched helical structure that shows a very poor dynamic behavior: only variations on the elongation of the helix were obtained for o-poly-(S)-1 (Figures $7 b, c)$. 
CD spectra of o-poly-(R)-1 and o-poly-(R)-2 in different solvents show identical CD traces to their corresponding counterparts opoly-(S)-1 and o-poly-(S)-2 but with opposite sign due to their enantiomeric relationship (See SI).

\section{CONCLUSIONS}

In conclusion, we have demonstrated that it is possible to predict the dynamic and structural behavior of a PPA by a proper monomer design. Thus, we found that, in case of PPAs that bear an anilide linkage between the polyene and the pendant group, it is possible to generate the complete series of PPAs resulting from different aromatic substitution patterns. On the contrary, when the amide group used as linking agent is connected in the opposite way benzamide-, only the para- and meta- substituted polymers can be obtained, being it not possible to access the ortho-substituted polymers. These different synthetic properties of the PPA series bearing anilide or benzamide connections are related to the different helical scaffolds adopted by the corresponding parasubstituted polymers. Thus, while p-PPAs bearing an anilide connections can adopt cis-cisoidal polyene scaffolds, in the case of p-PPAs bearing a benzamide connection, the polyenes are always cis-transoidal. This difference is crucial for the possibility of preparing the ortho-substituted polymers. Thus, while cis-cisoidal PPAs $\left(\omega_{1}<90^{\circ}\right)$, can vary the dihedral angle between conjugated double bonds by more than $90^{\circ}$ before reaching a planar structure, 
in the cis-transoidal ones $\left(\omega_{1}>90^{\circ}\right)$, the turning range is smaller than $90^{\circ}$. This higher rotational freedom found in cis-cisoidal polymers is the main reason why the o-, $m$ - and $p$-PPA series of poly-(S)-1, poly-(S)-2 and poly-(S)-3 can be prepared, while we did not succeed in the preparation of o-PPAs bearing benzamides as connecting groups. In addition, from these studies we can also state that m-PPAs always show an equilibrium between two helical scaffolds, one very similar to the para-substituted one (compressed, $c^{-c}$ ) and one more stretched $(c-t)$, while orthosubstituted polymers always adopt a highly stretched -almost planar- c-t helix.

Finally, from these studies we found that the dynamic behavior is directly related to the aromatic substitution pattern of the PPA. Thus, while in para substituted PPAs it is possible to modulate the helical sense or elongation of the polymer by conformational changes at the pendants, in meta-substituted polymers these changes are more restricted. The ortho-substituted PPAs are the less dynamic of the series due to the location of the pendant groups closer to the internal parts of the helices. As a result, their conformational flexibility is restricted by steric hindrance.

These findings will allow the scientific community to design materials with structure and dynamic behavior closely related to a specific function. Therefore, scientists can create monomers 
2

3

4

5

6

7

8

that provide polymers with optimal structure/function relationships in fields such as chiral recognition, asymmetric synthesis, chiral stationary phases or sensing. ASSOCIATED CONTENT

Supporting Information. Materials and Methods; Synthesis of the Monomers; CD Studies of the Monomers; Synthesis of the Polymers; GPC Studies; Circular Dichroism and Ultraviolet Studies; Thermal Studies; AFM Studies; Response of the Polymers to External Stimuli. The following files are available free of charge.

AUTHOR INFORMATION

Corresponding Author

felix.freire@usc.es

ACKNOWLEDGMENT

Financial support from MINECO (CTQ2015-70519-P), Xunta de Galicia (ED431C 2018/30; Centro singular de investigación de Galicia accreditation 2016-2019, ED431G/09 and the European Regional Development Fund (ERDF) is gratefully acknowledged. We also thank Servicio de Nanotecnología y Análisis de Superficies (CACTI, UVIGO) .

\section{ABBREVIATIONS}

AFM, Atomic Force Microscopy; ap, Antiperiplanar; CD, Circular Dichroism; DCM, Dichloromethane, DMF, Dimethylformamide; DMSO, 
Dimethyl Sulfoxide; DSC, Differential Scanning Calorimetry; HOPG, Highly Oriented Pyrolytic Graphite; IR, Infrared; M, Minus; MPA, $\alpha$-Methoxy- $\alpha$-Phenylacetic Acid; NMR, Nuclear Magnetic Resonance; $P$, Plus; sp, Synperiplanar; PGME, Phenylglycine Methyl Ester; PPA, poly (phenylacetylene); STD, saturation-Transfer Difference; TGA, thermogrvimetric analysis; THF, tetrahydrofuran; VT-CD, Variable Temperature-Circular Dichroism.

REFERENCES

(1) Yashima, E.; Ousaka, N.; Taura, D.; Shimomura, K.; Ikai, T.; Maeda, K. Supramolecular Helical Systems: Helical Assemblies of Small Molecules, Foldamers, and Polymers with Chiral Amplification and Their Functions. Chem. Rev., 2016, 116, 13752.

(2) Yu, Z.; Hecht, S. Remote control over folding by light. Chem. Commun., 2016, 52, 6639.

(3) Le Bailly, B. A. F.; Clayden, J. Dynamic foldamer chemistry. Chem. Commun., 2016, 52, 4852.

(4) Schwartz, E.; Koepf, M.; Kitto, H. J.; Nolte, R. J. M.; Rowan, A. E. Helical poly(isocyanides): past, present and future. Polym. Chem. 2011, 2, 33.

(5) Iida, H.; Yashima, E. Synthesis and Application of Helical Polymers with Macromolecular Helicity Memory, in Polymeric Chiral 
Catalyst Design and Chiral Polymer Synthesis, ed. S. Itsuno, John Wiley \& Sons, Hoboken, NJ, USA, 2011, ch. 7, p. 201.

(6) Rosen, B. M.; Wilson, C. J.; Wilson, D. A.; Peterca, M.; Imam, M. R.; Percec, V. Dendron-Mediates Self-Assembly, Disassembly, and Self-Organization of Complex Systems. Chem. Rev., 2009, 109, 6275.

(7) Yashima, E.; Maeda, K.; Iida, H.; Furusho, Y.; Nagai, K. Helical Polymers: Synthesis, Structure and Functions. Chem. Rev., 2009, 109, 6102.

(8) Rudick, J. G.; Percec, V. Induced Helical Backbone Conformations of Self-Organizable Dendronized Polymers. Acc. Chem. Res., 2008, 41, 1641.

(9) Pijper, D.; Feringa, B. L. Control of dynamic helicity at the macro- and supramolecular level. Soft Matter, 2008, 4, 1349.

(10) E. Yashima and K. Maeda, in Foldamers: Structure, Properties, and Applications, ed. S. Hecht and I. Huc, Wiley-VCH, Weinheim, 2007, pp. 331 .

(11) Yashima, E.; Maeda, K.; Furusho, Y. Single- and DoubleStranded Helical Polymers. AcC. Chem. Res., 2008, 41, 1166.

(12) Lam, J. W. Y.; Tang, B. Z. Functional Polyacetylenes. AcC. Chem. Res., 2005, 38, 745. 
(13) Huc, I. Aromatic Oligoamide Foldamers. Eur. J. Org. Chem., $2004,17$.

(14) Cornelissen, J. J. L. M.; Rowan, A. E.; Nolte, R. J. M.; Sommerdijk, N. A. J. M. Chiral Architectures from Macromolecular Building Blocks. Chem. Rev., 2001, 101, 4039.

(15) Hill, D. J.; Mio, M. J.; Prince, R. B.; Hughes T. S.; Moore, J. S. A Field Guide to Foldamers. Chem. Rev., 2001, 101, 3893.

(16) Nakano T.; Okamoto, Y. Synthetic Helical Polymers: Conformation and Function. Chem. Rev., 2001, 101, 4013.

(17) Gellman, S. H. Foldamers: A Manifesto. AcC. Chem. Res., 1998, 31,173

(18) Maeda, K.; Hirose, H.; Okoshi, N.; Shimomura, K.; Wada, Y.; Ikai, T.; Kanoh, S.; Yashima, E. Direct Detection of Hardly Detectable Hidden Chirality of Hydrocarbons and Deuterated Isotopomers by a Helical Polyacetylene trough Chiral Amplification and Memory. J. Am. Chem. Soc., 2018, 140, 3270.

(19) Maeda, K.; Yashima, E. Dynamic Helical Structures: Detection and Amplification of Chirality. Top. Curr. Chem., 2017, 375, 72.

(20) Pauly, A. C.; Theato, P. Toward Photopatternable Thin Film Optical Sensors Utilizing Reactive Polyphenylacetylenes. Macromol. Rapid Commun. 2013, 34, 516. 
(21) Yashima, E.; Maeda, K. Chirality responsive helical polymers. Macromolecules, 2008, 41, 3.

(22) Maeda, K.; Morioka, k.; Yashima, E. Synthesis and Chiral Sensing Properties of Poly[ (phenyleethynylene)-alt(carboxybiphenyleneethynylene)] s. Macromolecules, 2007, 40, 1349.

(23) Maeda, K.; Mochizuki, H.; Watanabe, M.; Yashima, E. Switching of Macromolecular Helicity of Optically Active Poly (phenylacetylene)s of Optically Active Poly (phenylacetylene)s Bearing Cyclodextrin Pendants Induced by Various External Stimuli. J. Am. Chem. Soc., 2006, 128, 7639.

(24) Maeda, K.; Yashima, E. Dynamic Helical Structures: Detection and Amplification of Chirality. Top. Curr. Chem., 2006, 265, 47.

(25) Maeda, K.; Kamiya, N.; Yashima, E. Poly(phenylacetylene)s Bearing a Peptide Pendant: Helical Conformational Changes of the Polymer Backbone Stimulated by the Pendant Conformational Change. Chem.-Eur. J., 2004, 10, 4000.

(26) Onouchi, H.; Maeda, K.; Yashima, E. A Helical Polyelectrolyte Induced by Specific Interactions with Biomolecules in Water. $J$. Am. Chem. Soc. 2002, 123, 7441.

(27) Yashima, E.; Maeda, Y.; Matsushima, T.; Okamoto, Y. Preparation of polyacetylenes bearing an amino group and their 
application to chirality assignment of carboxylic acids by circular dichroism. Chirality, 1997, 9, 593.

(28) Anger, E.; Iida, H.; Yamaguchi, T.; Hayashi, K.; Kumano, D.; Crassous, D.; Vanthuyne, N.; Rousselc, C.; Yashima, E. Synthesis and chiral recognition ability of helical polyacetylenes bearing helicene pendants. Polym. Chem., 2014, 5, 4909.

(29) Iida, H.; Miki, M.; Iwahana, S.; Yashima, E. Riboflavin-Based Fluorogenic Sensor for Chemo- and Enantioselective Detection of Amine Vapors Chem. - Eur. J., 2014, 20, 4257.

(30) Yashima, E.; Maeda, K.; Sato, O. Switching of a Macromolecular Helicity for Visual Distinction of Molecular Recognition Events. J. Am. Chem. Soc., 2001, 123, 8159.

(31) Hirose, D.; Isobe, A.; Quiñoá, E.; Freire, F.; Maeda, K. Three-State Switchable Chiral Stationary Phase Based on Helicity Control of an Optically Active Poly (phenylacetylene) Derivative by Using Metal Cations in the Solid State. J. Am. Chem. Soc., 2019, $141,8592$.

(32) Shimomura, K.; Ikai, T.; Kanoh, S.; Yashima, E.; Maeda, K. Switchable Enantioseparation Based on Macromolecular Memory of a Helical Polyacetylene in the Solid State. Nat. Chem., 2014, 6, 429. 
(33) Yamamoto, T.; Murakami, R.; Komatsu, S.; Suginome, M. Chirality-Amplifying, Dynamic Induction of Single-Handed Helix by Chiral Guests to Macromolecular Chiral Catalysts Bearing Boronyl Pendants as Receptor Sites. J. Am. Chem. Soc., 2018, 140, 3867.

(34) Yamamoto, T.; Murakami, R.; Suginome, M. Single-Handed Helical Poly(quinoxaline-2,3-diyls)s Bearing Achiral 4aminopyrid-3-yl Pendants as Highly Enantioselective, Reusable Chiral Nucleophilic Organocatalysts in the Steglich Reaction. J. Am. Chem. Soc., 2017, 139, 2557.

(35) Taura, D.; Hioki, S.; Tanabe, J.; Ousaka, N.; Yashima, E. Cobalt(II)-Salen-Linked Complementary Double-Stranded Helical Catalyst for Assymetric Nitro-Aldol Reaction. ACS Catal., 2016, 6, 4685. (d) Yuan-Zhen, K.; Nagata, Y.; Yamada, T.; Suginome, M. Majority-Rules-Type Helical Poly(quinoxaline-2,3-diyl)s as High Efficient Chirality-Amplification systems for Asymmetric Catalysis. Angew. Chem. Int. Ed., 2015, 54, 9333.

(36) Liu, L.; Long, Q.; Aoki, T.; Zhang, G.; Kaneko, T.; Teraguchi, M.; Zhang, Ch.; Wang, Y. A Helical Polyphenylacetylene Having Amino Alcohol Moieties Without Chiral Side Groups as a Chiral Ligand for the Asymmetric Addition of Diethylzinc to Benzaldehyde. Chirality, $2015,27,454$. 
(37) Iida, H.; Tang, Z.; Yashima, E. Synthesis and bifunctional asymmetric organocatalysis of helical poly(phenylacetylene)s bearing cinchona alkaloid pendants via a sulfonamide linkage. J. Polym. Sci., Part A: Polym. Chem., 2013, 51, 2869.

(38) Tang, Z.; Iida, H.; Hu, H.-Y.; Yashima, E. Remarkable Enhancement of the Enantioselectivity of an Organocatalyzed Asymmetric Henry Reaction Assisted by Helical Poly(acetylene)s Bearing Cinchona Alkaloid Pendants via an Amide Linkage. ACS Macro Lett., 2012, 1, 261.

(39) Megens, R. P.; Roelfes, G. Asymmetric catalysis with helical polymers. Chem. - Eur. J., 2011, 17, 8514.

(40) Nieto-Ortega, B.; Rodríguez, R.; Medina, S.; Quiñoá, E.; Riguera, R.; Casado, J.; Freire, F.; Ramírez, J. Sequential Induction of Chirality in Helical Polymers: From the Stereocenter to the Achiral Solvent. J. Phys. Chem. Lett. 2018, 9, 2266.

(41) Miyagawa, T.; Yamamoto, M.; Muraki, R.; Onuchi, H.; Yashima, E. Supramolecular helical assembly of an achiral cyanine dye in an induced helical amphiphilic poly(phenylacetylene) interior in water. J. Am. Chem. Soc., 2007, 129, 3676.

(42) Onuchi, H.; Miyagawa, T.; Morino, K.; Yashima, E. Assisted Formation of Chiral Porphyrin Homoaggregates by an Induced Helical 
Poly(phenylacetylene) Template and Their Chiral Memory. Angew. Chem Int. Ed. 2006, 45, 2381.

(43) Freire, F.; Quiñoá, E.; Riguera, R. Supramolecular assemblies from poly (phenylacetylene)s. Chem. Rev., 2016, 116, 1242.

(44) Arias, S.; Núñez-Martínez, M.; Quiñoá, E.; Riguera, R.; Freire, F. Simultaneous Adjustment of the Size and Helical Sense of Chiral Nanospheres and Nanotubes Derived from an Axially Racemic Poly (phenylacetylene). Small, 2016, 13, 1602398.

(45) Arias, S.; Freire, F.; Quiñoá, E.; Riguera, R. Nanospheres, Nanotubes, Toroids, and Gels with Controlled Macroscopic Chirality. Angew. Chem., Int. Ed. 2014, 53, 13720.

(46) Freire, F.; Seco, J. M.; Quiñoá, E.; Riguera, R. Helical Polymer-Metal Complexes: The Role of Metal Ion son the Helicity and the Supramolecular Architectures of Poly(phenylacetylene)s Adv. Polym. Sci., 2013, 262, 123.

(47) Freire, F.; Seco, J. M.; Quiñoá, E.; Riguera, R. Nanospheres with Tunable Size and Chirality from Helical Polymer-Metal Complexes. J. Am. Chem. Soc. 2012, 134, 19374.

(48) Rodríguez, R.; Quiñoá, E.; Riguera, R.; Freire, F. StimuliDirected Colorimetric Interconversion of Helical Polymers 
Accompanied by a Tunable Self-Assembly Process. Small, 2019, 15, 1805413.

(49) Rodríguez, R.; Quiñoá, E.; Riguera, R.; Freire, F. Multistate Chiroptical Switch Triggered by Stimuli-Responsive Chiral Teleinduction. Chem. Matter. 2018, 30, 2493.

(50) Lam, J. W. Y.; Tang, B. Z. Liquid-crystalline and lightemitting polyacetylenes. J. Polym. Sci., Part A: Polym. Chem. 2003, 41,2607

(51) Freire, F.; Quiñoá, E.; Riguera, R. Chiral nanostructure in polymers under different deposition conditions observed using atomic force microscopy of monolayers: Poly (phenylacetylenes)s as a case study. Chem. Commun., 2016, 53, 481.

(52) Ohsawa, S.; Sakurai, S.-I.; Nagai, K.; Banno, M.; Maeda, K.; Kumaki, J.; Yashima, E. J. Am. Chem. Soc., 2011, 133, 108.

(53) Yashima, E. Synthesis and structure determination of helical polymers. Polym. J., 2010, 42, 3 .

(54) Kumaki, J.; Sakurai, S.-I.; Yashima, E. Visualization of synthetic helical polymers by high-resolution atomic forcé microscopy. Chem. Soc. Rev., 2009, 38, 737.

(55) Sakurai, S.-I.; Ohsawa, K.; Nagai, K.; Okoshi, K.; Kumaki, J.; Yashima, E. Two-Dimensional Helix-Bundle Formation of a 
Dynamic Helical Poly(phenylacetylene) with Achiral Pendant Groups on Graphite. Angew. Chem., Int. Ed., 2007, 46, 7605.

(56) Okoshi, K.; Sakurai, S.; Ohsawa, J. K.; Yashima, E. TwoDimensional Hierarchical Self-Assembly of One-Handed Helical Polymers on Graphite. Angew. Chem., Int. Ed., 2006, 45, 1245.

(57) Sakurai, S.-I.; Okoshi, K.; Kumaki, J.; Yashima, E. TwoDimensional Surface Chirality Control by Solvent-Induced Helicity Inversion of a Helical Polyacetylene on Graphite. J. Am. Chem. SoC. 2006, 128, 5650 .

(58) Nishimura, T.; Takatani, K.; Sakurai, S.; Maeda, K.; Yashima, E. A Helical Array of Pendant Fullerenes on an Optically Active Polyphenylacetylene. Angew. Chem., Int. Ed., 2002, 41, 3602.

(59) Rodríguez, R.; Ignés-Mullol, J.; Sagués, F.; Quiñoá, E.; Riguera, R.; Freire F. Helical sense selective domains and enantiomeric superhelices generated by Langmuir-Schaefer deposition of an axially racemic chiral helical polymer. Nanoscale, 2016, 8, 3362 .

(60) Kumaki, J. Observation of polymer chain structures in twodimensional films by atomic force microscopy. Polym. J., 2016, 48, 3. 
(61) Percec, V.; Rudick, J. G.; Wagner, M.; Obata, M.; Mitchell, C. M.; Cho, W.-D.; Magonov, S. N. AFM Visualization of Individual and Periodic Assemblies of a Helical Dendronized Polyphenylacetylene og Graphite. Macromolecules, 2006, 39, 7342.

(62) Balagurusamy, V. S. K.; Lowe, J. N.; Glodde, M.; Weichold, O.; Chung, K. J.; Ghionni, N.; Magonov, S. N.; Heney, P. A. Synthesis, Structural Analysis, and Visualization of a Library of dendronized Polyphenylacetylenes. Chem.- Eur. J., 2006, 12, 5731.

(63) Arias, S.; Bergueiro, J.; Freire, F.; Quiñoá, E.; Riguera, R. Chiral Nanostructures from Helical Copolymer-Metal Complexes: Tunable Cation- Interactions and Sergeants and Soldiers Effect. Smal1, 2016, 12, 238.

(64) Bergueiro, J.; Freire, F.; Wendler, E. P.; Seco, J. M.; Quiñoá, E.; Riguera, R. The ON/OFF switching by metal ions of the "Sergeants and Soldiers" chiral amplification effect on helical poly (phenylacetylene)s. Chem. Sci. 2014, 5, 2170.

(65) Freire, F.; Seco, J. M.; Quiñoá, E.; Riguera, R. Chiral amplification and helical-sense tuning by mono- and divalent metal son dynamic helical polymers. Angew. Chem., Int. Ed. 2011, 50, 11692 .

(66) Jain, V.; Cheon, K.-S.; Tang, K.; Jha, S.; Green, M. M. Chiral Cooperativity in Helical Polymers. Isr. J. Chem. 2011, 51, 1067. 
(67) Nishimura, T.; Ohsawa, S.; Maeda, K.; Yashima, E.A helical array of pendant fullerenes on a helical poly(phenylacetylene) induced by non-covalent chiral interactions. Chem Commun., 2004, 646.

(68) Green, M. M.; Park, J.-W.; Sato, T.; Teramoto, A.; Lifson, S.; Selinger, R. L. B.; Selinger, J. V. The Macromolecular Route to Chiral Amplification. Angew. Chem. Int. Ed. 1999, 38, 3138. (69) Yashima, E.; Maeda, K.; Okamonoto, Y. Memory of macromolecular helicity assisted by interaction with achiral small molecules. Nature, 1999, 399, 449.

(70) Jha, S. K.; Cheon, K.-S.; Green, M. M.; Selinger, J. V. Chiral Optical Properties of a Helical Polymer Synthesized from Nearly Racemic Chiral Monomers Highly Diluted with Achiral Monomers. J. Am. Chem. Soc., 1999, 121, 1665.

(71) Green, M. M.; Garetz, B. A.; Muñoz, B.; Chang, H. P.; Hoke, S.; Cooks, R. G. Majority Rules in the Copolimerization of Mirror Image Isomers. J. Am. Chem. SoC., 1995, 117, 4181.

(72) Green, M.M.; Peterson, N.C.; Sato, T.; Teramoto, A.; Cook, R.; Lifson, S. A Helical Polymer with Cooperative Response to Chiral Information. Science, 1995, 268, 1860.

(73) Arias, S.; Núñez-Martínez, M.; Quiñoá, E.; Riguera, R.; Freire, F. A general route to chiral nanostructures from helical 
polymers: P/M switch via dynamic coordination. Polym. Chem., 2017, 8,3740

(74) Van Leeuwen, T.; Heideman, G. H.; Zhao, D.; Wezenberg, S. J.; Feringa, B. L.; In situ control of polymer helicity with a noncovalently bound photoresponsive molecular motor dopant. Chem. Commun., 2017, 53, 6393.

(75) Alzubi, M.; Arias, S.; Louzao, I.; Quiñoá, E.; Riguera, R.; Freire, F. Multipodal dynamic coordination involving cation- $\pi$ interactions to control the structure of helical polymers. Chem. Commun., 2017, 53, 8573.

(76) Louzao, I.; Seco, J. M.; Quiñoá, E.; Riguera, R. Control of the helicity of poly (phenylacetylene)s: from the Conformation of the Pendant to the Chirality of the Backbone. Angew. Chem., Int. Ed. 2010, 49, 1430 .

(77) Hu, Y.; Liu, R.; Sanda, F.; Masuda, T. Synthesis of Glutamic Acid-Based Dendritic Helical Poly(phenylacetylene)s. Polym. J., $2007,40,143$.

(78) Goto, H.; Zhang, H. Q.; Yashima, E. Helix-Sense Inversion of Poly (phenylacetylene) Derivatives Bearing an Optically Active Substituent Induced by External Chiral and Achiral Stimuli. Macromolecules, 2003, 125, 2516. 
(79) Cobos, K.; Quiñoá, E.; Riguera, R.; Freire, F. Chiral to Chiral Communication in Polymers: A Unique Approach to Control Both Helical Sense and Chirality at the Periphery. J. Am. Chem. SoC. 2018, 140, 12239 .

(80) Alzubi, M.; Arias, S.; Rodríguez, R.; Quiñoá, E.; Riguera, R.; Freire, F. "Chiral Conflict" as a New Tool to Create StimuliResponsive Materials Based on Dynamic Helycal Polymers. Angew. Chem. Int. Ed. 2019, 58, 13365.

(81) Tang, K.; Green, M. M.; Cheon, K. S.; Selinger, J. V.; Garetz, B. A. Chiral Conflict. The Effect of Temperature on the Helical Sense of a Polymer Controlled by the Competition between Structurally Different Enantiomers: From Dilute solution to the Lyotropic Liquid Crystal State. J. Am. Chem. Soc. 2003, 125, 7313. (82) Arias, S.; Rodríguez, R.; Quiñoá, E.; Riguera, R.; Freire, F. Chiral Coalition in the Enhancement of Copolymers: The Role of the Absolute Configuration of Comonomers. J. Am. Chem. Soc., 2018, 140,667 .

(83) Ishidate, R.; Markvoort, A. J.; Maeda, K.; Yasjhima, E. Unexpectedly Strong Chiral Amplification of Chiral/Achiral and Chiral/Chiral Copolymers of Biphenylacetylenes and Furthers Enhancement/Inversion and Memory of the Macromolecular Helicity. J. Am. Chem. Soc., 2019, 141, 7605 . 
(84) Rodríguez, R.; Quiñoá, E.; Riguera, R.; Freire, F. Architecture of Chiral Poly(phenylacetylene)s: From Compressed/Highly Dynamic to stretched/Quasi-Static Helices. J. Am. Chem. Soc., 2016, 138, 9620.

(85) Leiras, S.; Freire, F.; Seco, Quiñoá, E.; Riguera, R. Reversible Assembly of Enantiomeric Helical Polymers: From Fibers to Gels. Chem. Sci., 2015, 6, 246.

(86) Leiras, S.; Freire, F.; Seco, J. M.; Quiñoá, E.; Riguera, R. Controlled Modulation of the Helical Sense and the Elongation of Poly (phenylacetylene)s by Polar and Donor Effects. Chem. Sci., 2013, 4, 2735 .

(87) Cheuk, K. K. L.; Li, B. S.; Lam, J. W. Y.; Tang, B. Z . Synthesis, Chain Helicity, Assembling Structure, and Biological Compatibility of Poly(phenylacetylene)s Containing l-Alanine Moieties Macromolecules, 2008, 41, 5997.

(88) Sanda, F.; Terada, K.; Masuda, T. Synthesis, Chiroptical Properties, and pH Responsibility of Aspartic Acid- and Glutamic Acid-Based Helical Polyacetylenes. Macromolecules, 2005, 38, 8149.

(89) Li, B. S.; Cheuk, K. K. L.; Ling, L.; Chen, J.; Xiao, X.; Bai C.; Tang, B. Z. Synthesis and Hierarchical Structures of Amphiphilic Polyphenyalacetylenes Carrying l-Valine Pendants. Macromolecules, 2003, 36, 77. 
(90) Cheuk, K. K. L.; Lam, J. W. Y.; Chen, J.; Laiand, M. L.; Tang, B. Z. Amino Acid-Containing Polyacetylenes: Synthesis, Hydrogen Bonding, Chirality Transcription, and Chain Helicity of Amphiphilic Poly(phenylacetylene)s Carrying l-Leucine Pendants. Macromolecules, 2003, 36, 5947.

(91) Suárez-Picado, E.; Quiñoá, E.; Riguera, R.; Freire, F. Poly (phenylacetylene) Amines: A General Route to Water-Soluble Helical Polyamines. Chem. Matter., 2018, 30, 6908.

(92) Wang, S.; Shi, G.; Guan, X.; Zhang, J.; Wan, X. Cis-Cisoid Helical Structures of Poly(3,5-disubstituted phenylacetylene)s Stabilized by Intramolecular $n-\pi^{\star}$ Interactions. Macromolecules, 2018, 51, 1251 .

(93) Wang, S.; Ferng, X.; Zhang, J.; Yo, P.; Guo, Z.; Li, Z.; Wan, X. Helical Conformations of Poly(3,5-disubstituted phenylacetylene)s Tuned by Pendant structure and Solvent. Macromolecules, 2017, 50, 3489.

(94) Wang, S.; Feng, X.; Zhao, Z.; Zhang, J.; Wan, X. Reversible Cis-Cisoid to Cis-Transoid Helical Structure Transition in Poly(3,5 disubstituted phenylacetylene)s. Macromolecules, 2016, 49,8407 
(95) Percec, V.; Rudick, J. G.; Peterca, M.; Heiney, P. A. Nanomecanical function from self-organizable dendronized helical polyphenylacetylenes J. Am. Chem. Soc., 2008, 130, 7503.

(96) Rudick, J. G.; Percec, V. Nanomechanical Function Made Possible by Suppressing Structural Transformations of Polyarylacetylenes. Macromol. Chem. Phys. 2008, 209, 1759.

(97) Feringa, B. L.; Browne, W. R. Macromolecules flex their muscles. Nature Nanotech., 2008, 3, 383.

(98) Rudick, J. G.; Percec, V. Helical chirality in dendronized polyarylacetylenes. New J. Chem., 2007, 31, 1083.

(99) Percec, V.; Peterca, M.; Rudick, J. G.; Aqad, E.; Imam, M. R.; Heiney, P. A. Self-Assembling Phenylpropyl Ether Dendronized Helical Polyphenylacetylenes. Chem.-Eur. J., 2007, 13, 9572.

(100) Percec, V.; Rudick, J. G.; Peterca, M.; Aqad, E.; Imam, M. R.; Heiney, P. A. Synthesis, structural, and retrostructural analysis of helical dendronized poly(1-naphthylacetylene)s. $J$. Polym. Sci., Part A: Polym. Chem., 2007, 45, 4974.

(101) Percec, V.; Peterca, M.; Rudick, J. G.; Aqad, E.; Imam, M. R.; Heiney, P. A. Self-Assembling Phenylpropyl Ether Dendronized Helical Polyphenylacetylenes. Chem.-Eur. J., 2007, 13, 9572. 
(102) Percec, V.; Aqad, E.; Peterca, M.; Rudick, J. G.; Lemon, L.; Ronda, J. C.; De, B. B.; Heiney, P. A., Meijer, E. W. Steric Communication of Chiral Information Observed in Dendronized Polyacetylenes. J. Am. Chem. Soc., 2006, 128, 16365.

(103) Percec, V.; Rudick, J. G.; Peterca, M.; Wagner, M.; Obata, M.; Mitchell, C. M.; Cho, W.-D.; Balagurusamy, V. S. K.; Heiney, P. A. Thermoreversible Cis-Cisoidal to Cis-Transoidal Isomerization of Helical Dendronized Polyphenylacetylenes. J. Am. Chem. Soc., 2005, 127, 15257.

(104) Ke, Z.; Abe, S.; Ueno, T.; Moruma, K. Rh-Catalyzed Polymerization of Phenylacetylene: Theoretical Studies of the Reaction Mechanism, Regioselectivity, and Stereoregularity. J. Am. Chem. Soc., 2011, 133, 7926.

(105) Mayershofer, M. G.; Nuyken, O. Living polymerization of substituted acetylenes. J. Polym. Sci., Part A: Polym. Chem., 2005, 43,5723

(106) Kishimoto, Y.; Eckerle, P.; Miyatake, T.; Ikariya T.; Noyori, R. Living Polymerization of Phenylacetylenes Initiated by Rh (C.tplbond. $\left.\mathrm{CC}_{6} \mathrm{H}_{5}\right)\left(2,5\right.$-norbodaridene) $\left[\mathrm{P}\left(\mathrm{C}_{6} \mathrm{H}_{5}\right)_{3}\right]_{2}$. J. Am. Chem. SoC., 1994, 116, 12131.

(107) Tabata, M.; Yang, W.; Yokota, K. Polymerization of mClorophenylacetylene Initiated by [Rh(norboradiene) $\left.\mathrm{Cl}_{2}\right]_{2}^{-}$ 
Triethylamine Catalyst Containing Long-Lived Propagation Species. Polym. J., 1990, 22, 1105.

(108) Furlani, A.; Napoletano, C.; Russo, M. V.; Feast, W. Stereoregular polyphenylacetylene. Polym. Bull., 1986, 16, 311.

(109) Simionescu, C. I.; Percec, V. J.Thermal cis-trans isomerization of cis-transoidal polyphenylacetylene. Polym. Sci., Polym. Chem. Ed., 1980, 18, 147.

(110) Simionescu, C. I.; Percec, V.; Dumitrescu, S. Polymerization of Acetylenic Derivatives. Isomers of Polyphenylacetylene. J. Polym. Sci., Polym. Chem. Ed., 1977, 15, 2497.

(111) Liu, L.; Namikoshi, T.; Zang, Y.; Aoki, T.; Hadano, S.; Abe, Y.; Wasuzu, I.; Tsutsuba, T.; Teraguchi, M.; Kaneko, T. Top-Down Preparation of Self- Supporting Supramolecular Polymeric Membranes Using Highly Selective Photocyclic Aromatization of Cis-Cisoid Helical Poly (phenylacetylene)s in the Membrane State. J. Am. Chem. SoC. 2013, 135, 602 .

(112) Fernández, B.; Rodríguez, R.; Quiñoá, E.; Riguera, R.; Freire. Decoding the ECD Spectra of Poly(phenylacetylene)s: Structural Significance. ACS Omega, 2019, 4, 5233.

(113) Fernández, B.; Rodríguez, R.; Rizzo, A.; Quiñoá, E.; Riguera, R.; Freire, F. Predicting the Helical sense of 
Poly(phenylacetylene)s from their Electron Circular Dichroism Spectra. Angew. Chem. Int. Ed., 2018, 57, 3666.

(114) Rodríguez, R.; Arias, S.; Quiñoá, E.; Riguera, R.; Freire, F. The role of the secondary structure of helical poly(phenylacetylene)s in the formation of nanoparticles from polymer-metal complexes (HPMCs). Nanoscale, 2017, 9, 17752.

TOC

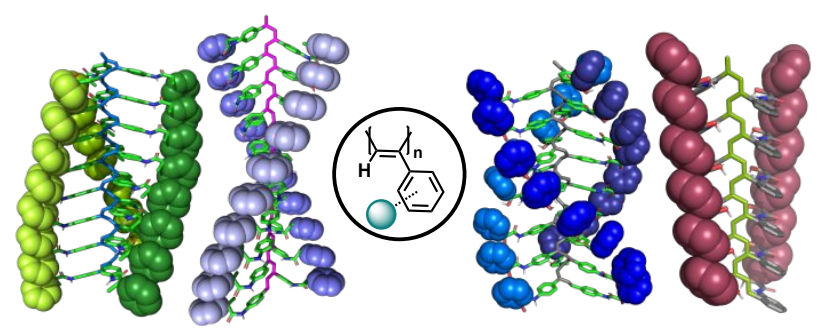

ACS Paragon Plus Environment 